\title{
Study on Stability of Saturated Rock-Like Material Containing Pre-Existing Crack
}

\author{
Foutou Matsoulou Ray ${ }^{\text {a,b* }}$, Gao xiang ${ }^{\text {a,b }} \&$ Ngambua N.Rene $^{\text {a,b, }}$ \\ ${ }^{a}$ College of Mining Engineering, Taiyuan University of Technology, Taiyuan, Shanxi 030024, China \\ ${ }^{\mathrm{b}}$ Key Laboratory of In-situ Property-improving Mining of Ministry of Education, Taiyuan University of \\ Technology, Taiyuan, Shanxi 030024, China
}

\begin{abstract}
The stability of the rock mass is generally constituted by the presence and the behavior of the discontinuities. The flow of water in a rock mass is one of the parameters that considerably affect fractured rock behavior, strength, and stability. This study proposes triaxial compression test to determine the stress, strain, and failure modes of the penetrating fractured rock mass under static load, and to reveal the relationship between its strength, deformation and strain rate, fracture slope, and fracture water. ABAQUS simulation proposes to identify material damage plasticity and generate stress and displacement of the specimen. Two kinds of the specimens which were plane and rough surface have been tested under drying state and saturated state conditions. The specimens were made with the slope of $30^{\circ}, 45^{\circ}$, and $60^{\circ}$. Three-dimensional scanning is carried to illustrate the surface of the rock samples. Compressive strength of drying state specimens performed better than saturated state. The results also show that the greater slopes attained lower compressive strength and the rough surface attained higher compressive strength compared to plane surface. The simulation results attained similar trend with the experiment results.
\end{abstract}

Keywords: Compressive Strength, Triaxial-Compression Test, ABAQUS, Strain, Saturation, Fissured Rock Mass.

\section{INTRODUCTION}

Rock is the product of geological changes and it is a discontinuous complex composed by a weak plane, sliding plane, interlayer and fault of various crystals. Due to the medium's discontinuity caused by the rock joints, the medium's discontinuous interface is called a structural plane. Discontinuity is one of the intrinsic characteristics of the rock mass since their mechanical properties are far lower than that rock matrix, it is the geometric and mechanical properties of discontinuous surface rather than the rock matrix's specific properties that determine rock mass. The influence of discontinuity on the properties of the rock mass, shear strength of the fractured rock mass and water on shear strength of rock mass are helpful to solve the problem of stability of different rock mass.

The stability of the rock mass is generally constituted by the presence and the behavior of the discontinuities. The discontinuities are able to become considerable weakness and deformability of the rock masses. It is through these discontinuities that water has the ability to circulate. These discontinuities having a predominant influence on the characteristics of the massif that is on its mechanical and hydraulic behaviors, it is therefore important to know both the mechanical behavior as well as the hydraulic behavior of the fractures and their possible coupling. The flow of water in a rock mass is one of the parameters that considerably affect fractured rock behavior, strength, and stability.

Water presence practically has discovered reducing the shear strength of rough surface joints, although it does not significantly influence the strength of plane surface. The shear strength depends on the compressive strength which is reduced by the water presence [1]. The presence of water pressure in fractures significantly reduces the coefficient of safety against rockslide and landslide according to numerical modeling results $[2,3]$.

When hydraulic fracture takes place, one has to take into account additional complex physical processes associated with the fluid and the fluid/solid interaction. The fluid injected into the rocks at a high pressure, which causes in increased pore pressure around

www.ijasre.net

Page 92 
the medium and encourages to rock deformation and damage. The rock damage process is also accompanied by the micro cracks forming, which leads to two effects: an increased the rock permeability, which affects the fluid flow and pore pressure, and the stiffness degradation of the rock, which affects the rock deformation and stress state. The above two processes are fully coupled, and nonlinear [4].

Many studies were conducted by researchers in order to understand the rock mass stability and mechanical properties of the rocks. Buocz et al (2013) studied shear strength test on intact and fractured rocks. The maximal and residual angle of friction had small different between the maximal and residual values. The properties of infill material, its mineralogy, thickness and surface roughness have a high influence on the shear strength [5]. Wanniarachchi et al (2018) proposed high pressure triaxial method to investigate the effect of fracturing fluid on hydraulic fracturing characteristics, including breakdown pressure and energy release in siltstone and to evaluate the fracture permeability of hydraulically-fractured siltstone specimens. The foam fracturing induced a complex twisted fracture and the fracture occurred throughout the specimen. The foam fracturing emitted more energy than water fracturing during the fracturing process. According to the measured permeability values, the fracture permeability of foam fractured specimens was about $5 \times 105$ times greater than that of intact and water-fractured specimens [6]. The increasing confining pressure, permeability decreases and interestingly permeability decreases with increasing injection pressure [7,8,9,10].

In fracture generation, hydration swelling and anisotropy stress also become factors putting on fracture initiation and propagation. The higher anisotropy stress leads into larger induced fracture geometry [11,12]. Zang and Ranjith (2019) investigated the fracturing behaviors of water-based fracturing (WBF) and CO2-based fracturing (CBF). CBF was able to decrease the breakdown pressure and $\mathrm{CBF}$ produced high loose particles. Breakdown pressure can be lower because of high pore pressure along with the infiltration increase of injected fluid [13,14]. Lower viscosity fluid also leads low breakdown pressure $[15,16,17]$.

Zhou et al (2008) investigated the hydraulic fractures mechanism which interact with pre-existing fractures and shear strength. Shear strength of pre-fracture, differential horizontal principal stress and the angles influenced toward fracture propagation behaviors $[18,19]$. Hydraulic fractures were found as vertical fractures that interacting with pre-existing fracture in the normal stress regime [18,20]. Gudmundsson et al (2010) found that local stress of the fault zone, heterogeneities, and discontinuities were able to determine propagation, deflection and arrest of the fractures [21,22,23,24]. Arrested fractures influenced on permeability development and fluid transport $[21,25]$.

This study proposed to understand the rock mass stability by conducting triaxial compression stress to get stress and strain behavior of the rock under dry and water saturation states. Simulation of concrete damage plasticity using ABAQUS was conducted to define the fracture and damage behavior of the specimens. Further the experiment results were compared with the simulation results.

\section{Materials and experimental methodology}

\subsection{Specimen preparation}

First, a three-dimensional topography scan was performed on the natural fracture surface to obtain point cloud data. Then it imported into COMSOL to build a three-dimensional model that further was printed using a 3D printer. There are 6 models which are plane and rough surface models with slope of $30^{\circ}, 45^{\circ}$, and $60^{\circ}$.

Ordinary Portland cement was used for fabrication inside a cylindrical mold. The cylinder and the PVC material were coated with lubricating oil to facilitate sample fabrication. The specimen was consisted of a mixture of water, cement and sand with the ratio 1:2:3. The 3D model put on the mold and the mixture then was filled into the mold for 24 to 48 hours. Those specimens took out from the mold and were being cured. The obtained samples were soaked in the water for 7 days. Cubical test specimen of dimension $50 \mathrm{~mm}$ in diameter and $100 \mathrm{~mm}$ in height $(\Phi 50 \mathrm{~mm} \times 100 \mathrm{~mm})$ with plane and rough surface models with slope of $30^{\circ}$, $45^{\circ}$ and $60^{\circ}$ were used for the test. The dimensions of the samples were being reviewed to get desired samples as shown in figure 1.1 . 


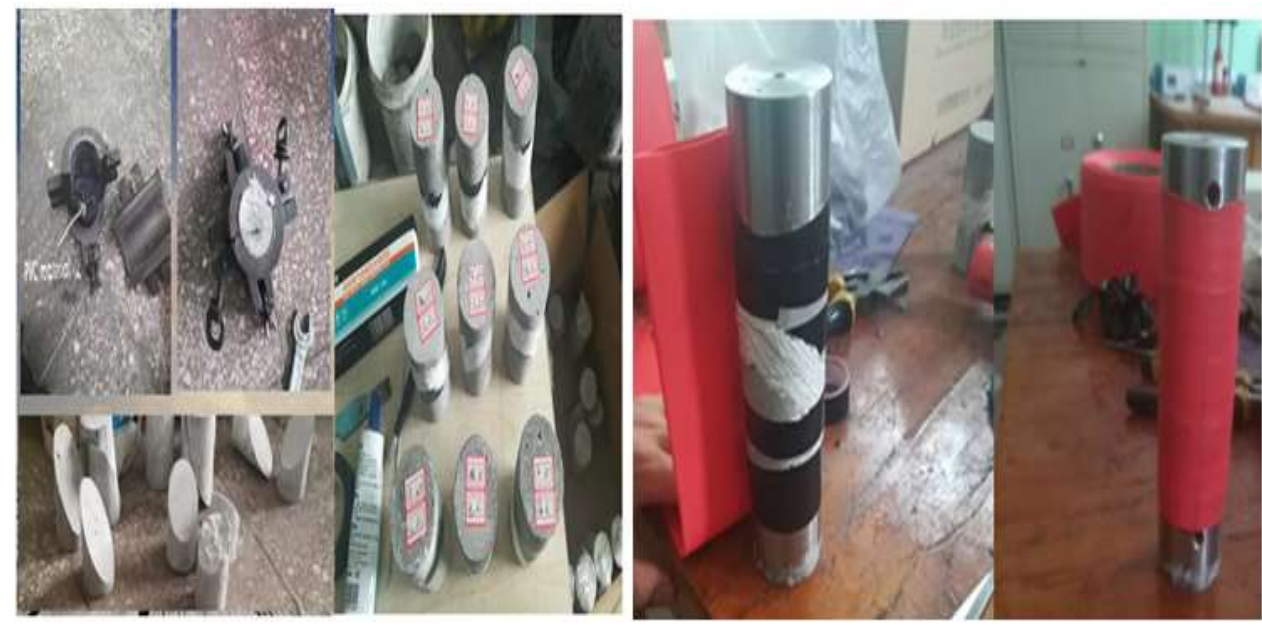

Figure 1. Test Specimens

\subsection{Experimental}

Triaxial Drained Compression (CD) test has been conducted to study the stability of rock mass. The experiment was carried out using YAW-3000 micro computer-controlled electro-hydraulic servo pressure testing machine. The maximum confining pressure of the triaxial test system is $70 \mathrm{MPa}$, the maximum axial pressure is $3000 \mathrm{KN}$, and the maximum pore water pressure is $40 \mathrm{MPa}$. Axial stress was obtained by servo-controlled loading. The axial and hoop deformation can be measured in real time through extensometers with an accuracy of $0.001 \mathrm{~mm}$. The testing devices were set up as in the figure 2 .

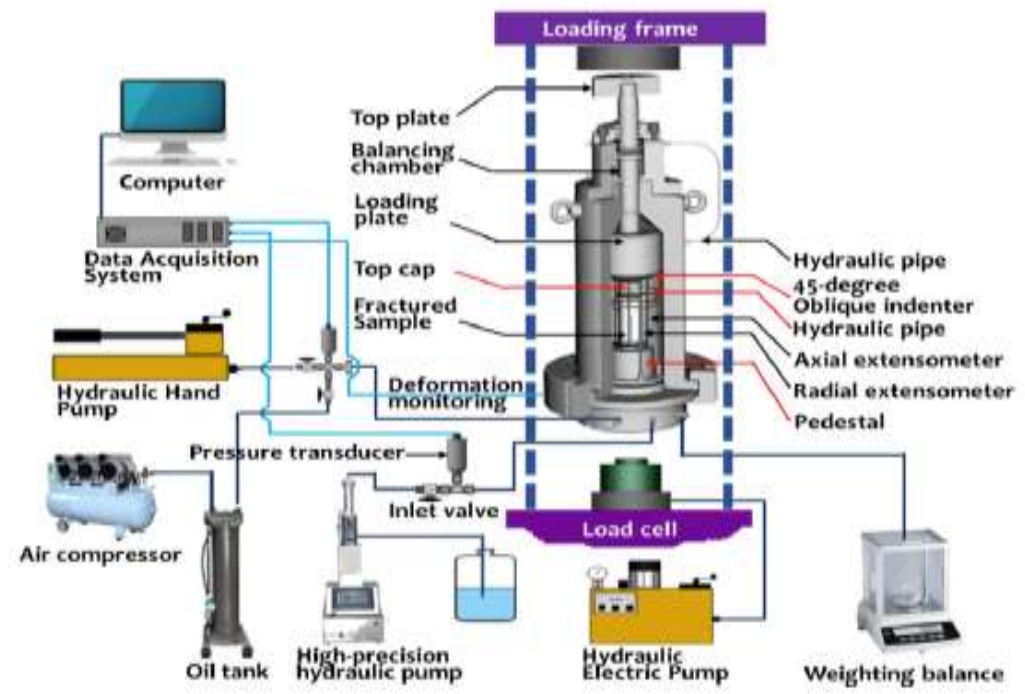

Figure 2. Experimental setup

\subsubsection{Triaxial Cell}

The triaxial cell is a component where the specimen was placed and the pressure and the load were provided. The triaxial top connects to the loading frame. The triaxial is built of some parts which are a basement, a pressure bell, a balancing cell and a load system. In this cell, the specimen is put on between basement and top cap by interposing between porous discs. A membrane aims to prevent movement among parts according to ASTM D4767-95 [26, 27]. A loading system passes on the vertical load to the specimens from the load frame.

A pressure bell embodies to the basement, the watertight chamber is used to apply isotropic confining pressure by injecting the silicon oil. A balancing cell exists over the pressure bell. A discoid piston area corresponds with the cross area of the load shaft omitting the load shaft's movement in the pressure of the confining oil and only the vertical. It proposes to measure the deviatoric load only which is applied to the sample [27].

\subsubsection{Loading frame}

The loading frame applies the vertical load to the specimen through the loading frame that enables the material behavior to be evaluated. The movement of the sliding plate is provided by a screw mechanism that is controlled by a micro-processor 
which connected to the load cell. The peak of vertical displacement is equal to $100 \mathrm{~mm}$. The stress paths are able to perform both under displacement or load controlled mode.

\subsubsection{Hydraulic Actuators}

Hydraulic servo-controlled actuator provides pressure the confining fluids on the bottom of the specimen. The pressure to the fluid is produced by a piston in a steel cylinder vessel which is directly connected to the triaxial cell. The digital controllers propose to perform the test both under pressure or volume control. An additional perspex lung, connected to the air pressure circuit, helps filling the water drainage circuit and flushing the sample.

\subsubsection{Measuring system}

Measuring transducers are used to control and determine the triaxial testing. Those measurement devices of present study are:

- A load gauge measures the axial load that is applied to the sample. The axial loading device is able to determine the axial load with the accuracy within $1 \%$ [28].

- The measurement of the pressure on the triaxial cell (chamber pressure) and the pressure of the water at the bottom of the sample (back pressure) proposes sensor devices with the accuracy at $0.01 \mathrm{MPa}$. The maximum confining pressure of the device is $70 \mathrm{MPa}$ and the maximum axial pressure is up to $1000 \mathrm{KN}$. Further the maximum pore water pressure is $40 \mathrm{MPa}$. The fluid injection at a constant flow rate can perform maximum $30 \mathrm{ml} / \mathrm{min}$.

- A displacement measuring system proposes to determine the axial and radial deformations of the samples. The extensometer is used with the accuracy within $1 \mu \mathrm{m}$. Since this measurement includes as well the deformations of the triaxial cell, internal displacement measuring system was built on. It is a series of linear variable differential transformer which is able to be pasted on the membrane on the lateral surface of the specimen.

\subsubsection{Test control tools/ PC}

The acquisition and control system encompass the system of control and the measurement which are directly connected to form autonomous units. It further couples to a personal computer which carrying out the entire of experimental structures. PC is used to control and attain the data during experiment through software. The software functions to apply the procedure and parameters of the test. Data are generated and saved in a log file and are able to be set using commercial spreadsheets.

\subsection{Experimental procedure}

The experiment of consolidated drained test was carried out by firstly taking the specimen cap into axial load piston. Further fill the chamber with the liquid chamber. The next step is applying back pressure to the specimen. Apply consolidation phase which was isotropic consolidation to make the specimen reaching equilibrium in a drainage state at the effective consolidation stress in order to attain a strength determination. Apply the shear with the piston slightly above the specimen cap and before the piston contact with the specimen by adjusting the axial load measuring device to the initial friction and thrust. Then continue applying the axial loading. Keep the cell constantly being pressured and record the loading, displacement, axial deformation and radial deformation. Close the drainage valves once the shear was completed and remove the specimen from the cell, then remove the membrane and seal.

Three-dimensional topography was conducted to analyze the surface of the specimens. The scanning process used 3D scanner of OKIO-H-200 which developed by Taiyuan 3D Technology Ci., Ltd. The OKIO-H-200 adopts high precision industrial CDD sensors with 1.31 million pixels, UHP cold light source. The range of scanning is up to $200 \times 1501100 \times 75 \mathrm{~mm}$ with the accuracy is $0.02 \sim 0.01 \mathrm{~mm}$. It has resolution about $0.15 \sim 0.07 \mathrm{~mm}$ and its single scanning time is less than 2 seconds. The three major devices are measuring head, $x-y$ positioning table and PC. The head is placed in a tripod holder. The $x-y$ positioning table is about $50 \mathrm{~cm}$ under the measuring head. The specimen was placed in the $x$-y positioning table. The laser of the measuring head was radiated to the specimen surface. The surface further was reflected and detected by the laser sensor. Positioning table of $x-y$ was moved horizontally in order to laser reaching all over surface of the specimen. PC recorded 3D illustration of the specimen that was reflected by the laser beam.

The concrete damage plastic (CDP) model of ABAQUS has been simulated to get damage model of concrete. The failure mechanism of compressive crushing was applied to simulate the failure evolution of concrete surface under tensile and compression loading. COMSOL was used to import the scanned model. The model was saved to be a Sat geometry file and further import the sat geometry to ABAQUS to determine interface friction. Displacement and load were also performed dynamically. Stiffness degradation variable was retrieved to understand the decrease of the stiffness unit which is caused by damage. 


\section{RESULTS AND DISCUSSION}

\subsection{Experimental Analysis}

A series of study carried out to perform consolidated-drained tri-axial compression test to understand the characteristic of rock mass stability. Three-dimensional scanning was conducted toward the surface of the rocks. Two kind of the specimen has been used which were drying state specimens and saturated state specimens with the slope of $30^{\circ}, 45^{\circ}, 60^{\circ}$. The loading speed of the experiment is $0.5 \mathrm{kN} / \mathrm{s}$.

\subsubsection{Displacement analysis for drying and saturated state}

Peak of displacements at every slope which are attained for drying state and saturated state are illustrated in the figure 3.1 and 3.2. Saturated state recorded lower displacement than the drying state specimens. Plane surfaces of $30^{\circ}$ slope displaced more than rough surfaces for both drying state and saturated state. However, plane specimens with $45^{\circ}$ and $60^{\circ}$ slopes displaced higher than rough surfaces. Reservedly the displacements of plane specimens with $45^{\circ}$ and $60^{\circ}$ did not occurred beyond rough surface for saturated state.

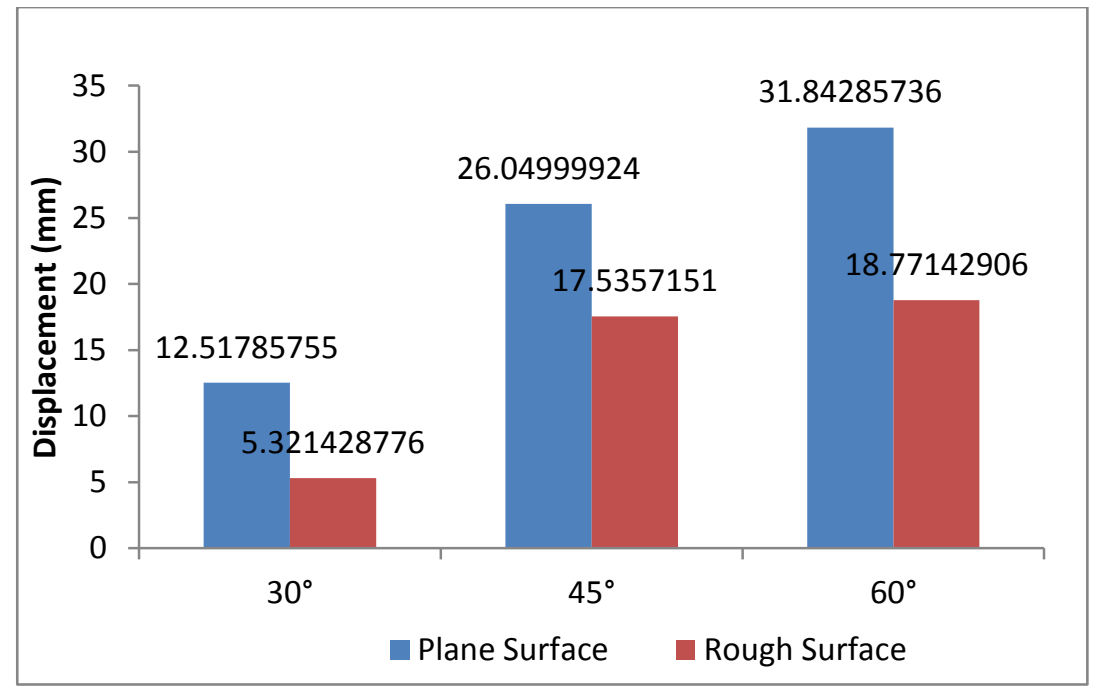

Figure 3.1 the peak of displacements for drying state

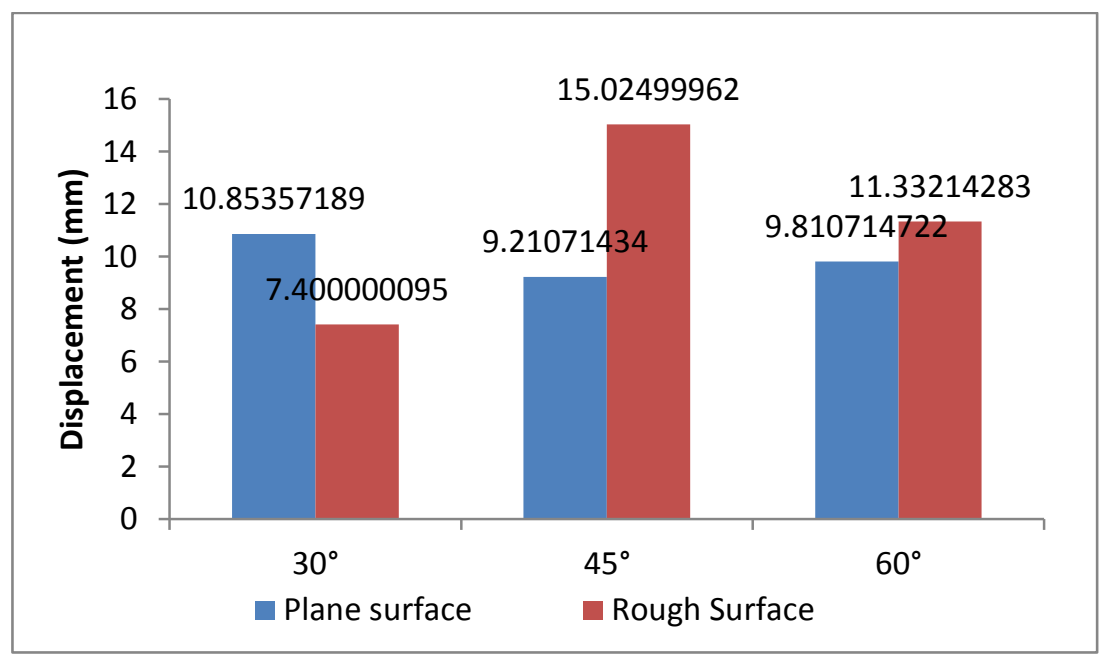

Figure 3.2 the peak of displacements for saturated state

It can be seen that the specimen displacement increased along with the higher slope for the drying state scenario. Meanwhile higher slope did not affect the displacement for the saturated state scenario because the highest displacement occurred to rough surface specimens with $45^{\circ}$ slope.

\subsubsection{Deformation analysis for drying and saturated state}

Axial strain refers to deformation of the rocks due to the compression. Deformation which was occurred during experiment is drawn in the figure 3.3 and 3.4. Plane surface of $30^{\circ}$ slope attained lower deformation compared to the rough surface for the drying state specimens. Reservedly the rough surface of $45^{\circ}$ and $60^{\circ}$ slopes attained lower deformation compared to the plane 
surfaces as figure 3.3. Saturated states recorded higher deformation for the plane surface of $30^{\circ}$ and $45^{\circ}$ slopes compared to rough surface. However, the plane surface of $60^{\circ}$ slopes attained lower deformation compared to the rough surface. The results also show that plane surface specimens of drying state deformed lesser compared with saturated state. In other hand, the rough surface specimens of drying state deformed more than saturated state.

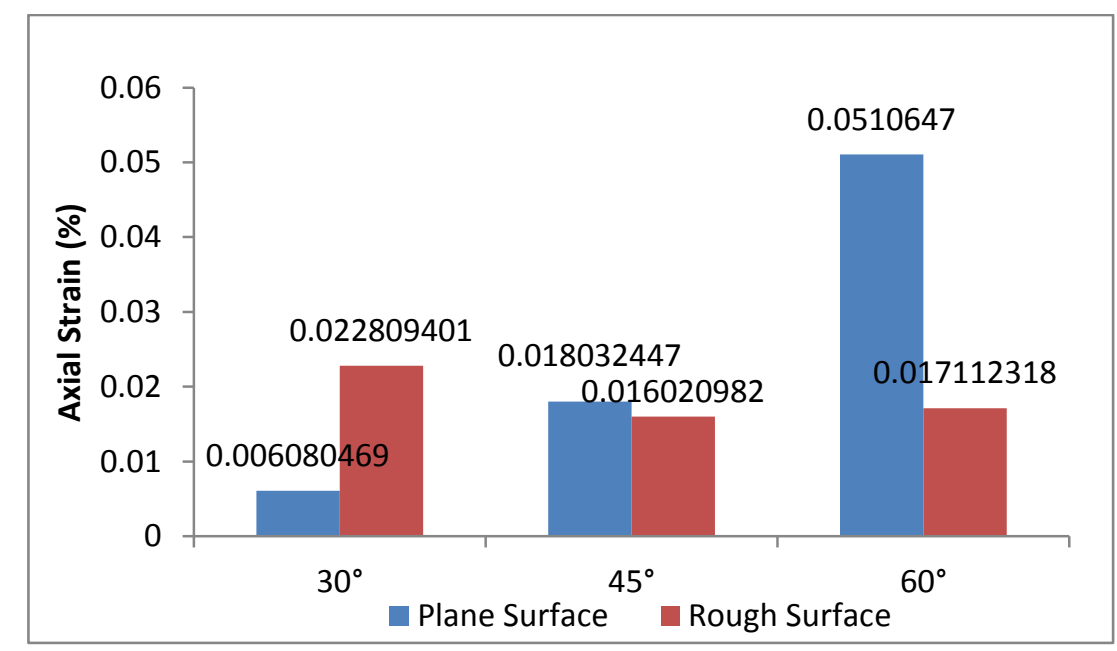

Figure 3.3 the peak of axial strains for drying state

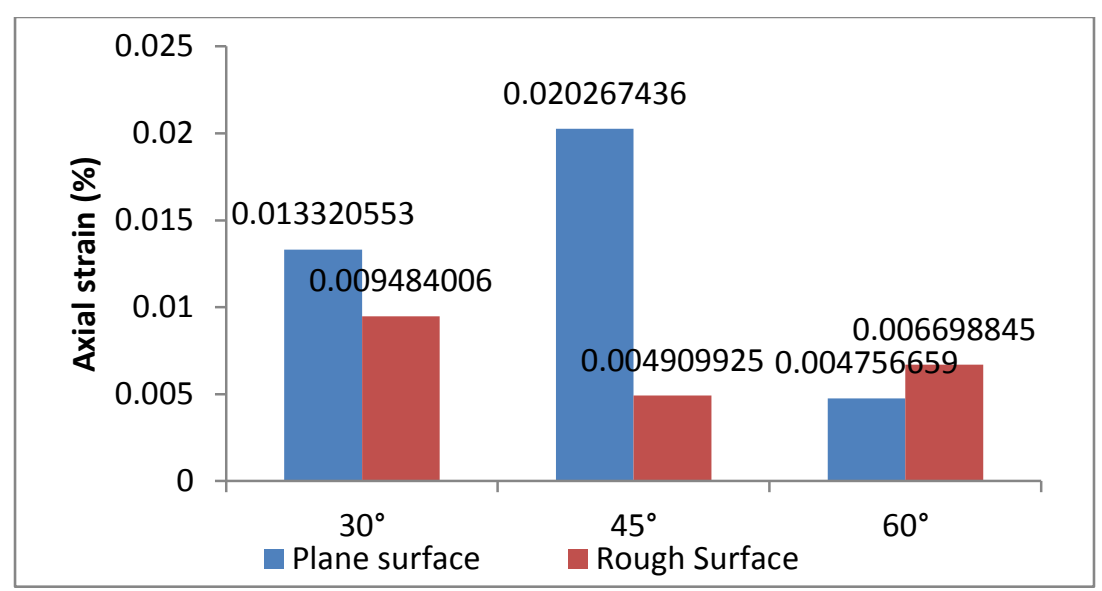

Figure 3.4 the peak of axial strains for saturated state

\subsubsection{Compressive strength analysis for drying and saturated state}

Compressive strength is the value of uniaxial compressive stress when the material completely fails. In other word, it is the capacity of a material or structure to withstand loads tending to reduce size, as opposed to which withstands loads tending to elongate. Figure 3.5 and 3.6 compare the compressive strength of drying state and saturated state specimens. 


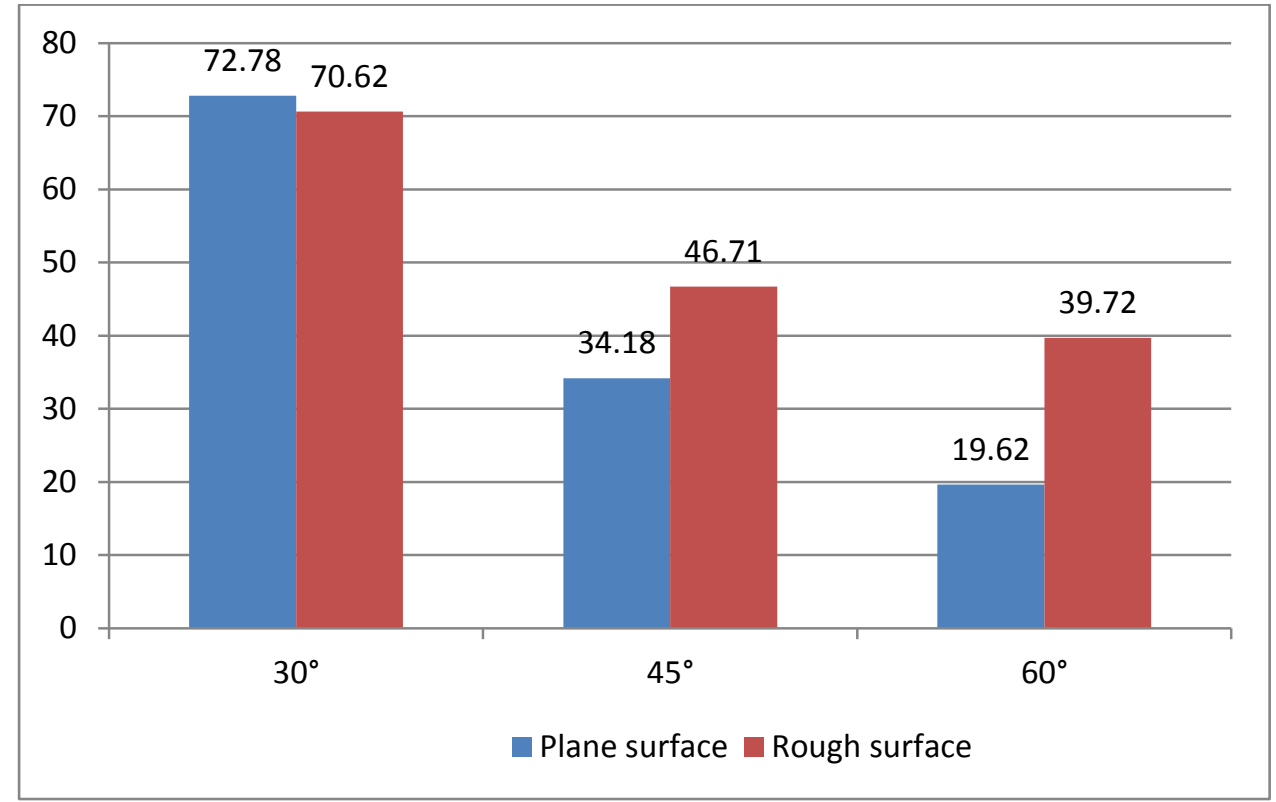

Figure 3.5 Compressive strength of drying state specimens

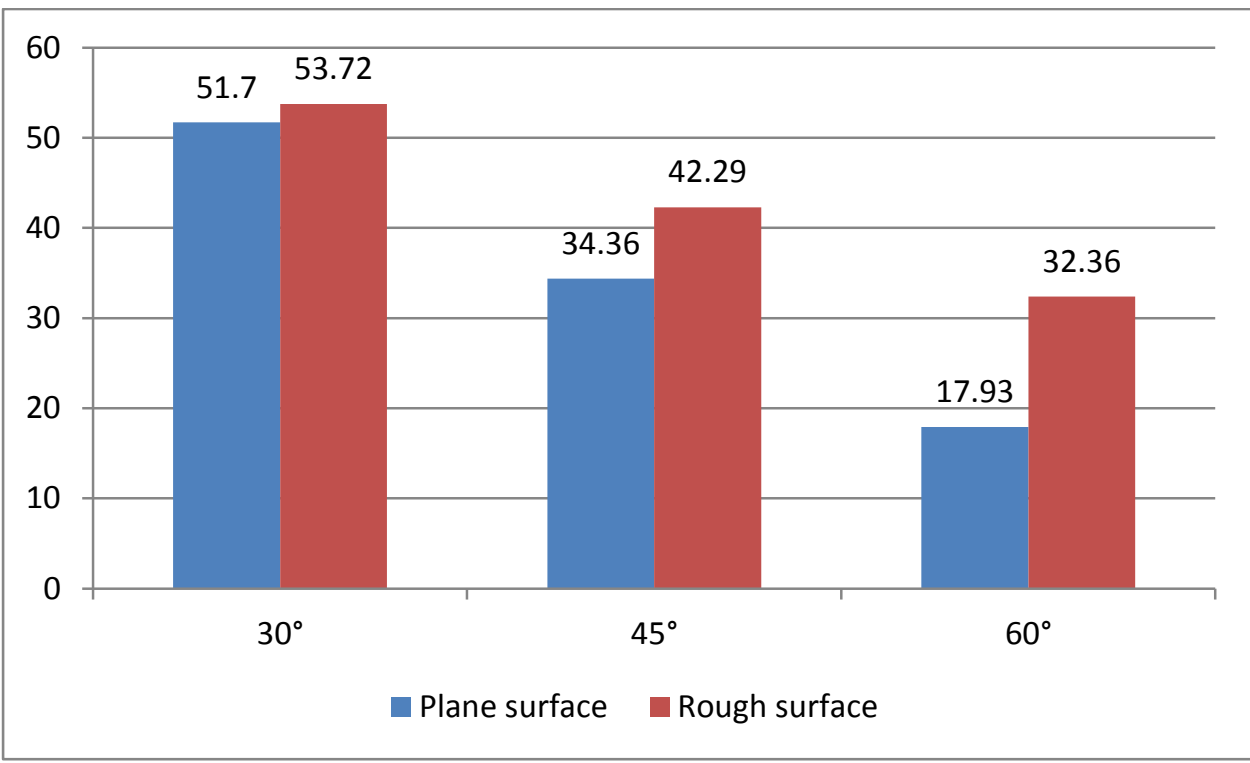

Figure 3.6 Compressive strength of saturated state specimens

The figures show that compressive strength of rough surface recorded higher than plane surface except for the drying state specimens with $30^{\circ}$ slope. Plane surface has higher compressive strength than rough surface for this scenario. It can be generally concluded that rough surfaces resist towards the load better than plane surfaces.

\subsubsection{Stress-displacement of drying state analysis}

In other results, the stress and displacement values which were measured by the data acquisition system during the test, the stressdisplacement relationship of the sample during the entire compression process are determined as illustrated in figure 3.7 and 3.8. The comparison of deviator and displacement for all scenarios of drying state can be seen in figure 3.8. Deviator stress of plane surface of $30^{\circ}$ slope moved steady at the initial of the test, but the displacement had happened rapidly. When the deviator stress was increased, the displacement increased up to more than $12 \mathrm{~mm}$ at deviator stress of approximately $72.78 \mathrm{MPa}$. The rough surface of $30^{\circ}$ showed less displacement. It was increased less than $2 \mathrm{~mm}$ at the initial deviator stress and the specimen only displaced about $5 \mathrm{~mm}$ at the maximum deviator stress which was approximately $70.62 \mathrm{MPa}$. However, the displacement kept increased although the stress decreased.

The result of $45^{\circ}$ slope is shown in the figure $3.7 \mathrm{~b}$. The displacement of plane surface attained $13 \mathrm{~mm}$ at the initial deviator stress. When the deviator stress increased, the displacement kept increased. The rough surface displacement was approximately $4 \mathrm{~mm}$ at the initial deviator stress and it kept increased until the end of the test. Although the stress decreased after its maximum stress 
about $46.71 \mathrm{MPa}$. In another result, plane and rough surfaces of $60^{\circ}$ slope shows similar trend with the rough surface of $45^{\circ}$ slope, the displacement increased steadily in the initial deviator stress and it kept increasing with the increase of the deviator stress. It also can be seen that the displacement was increasing although the deviator stress decreased for either plane or rough surface.

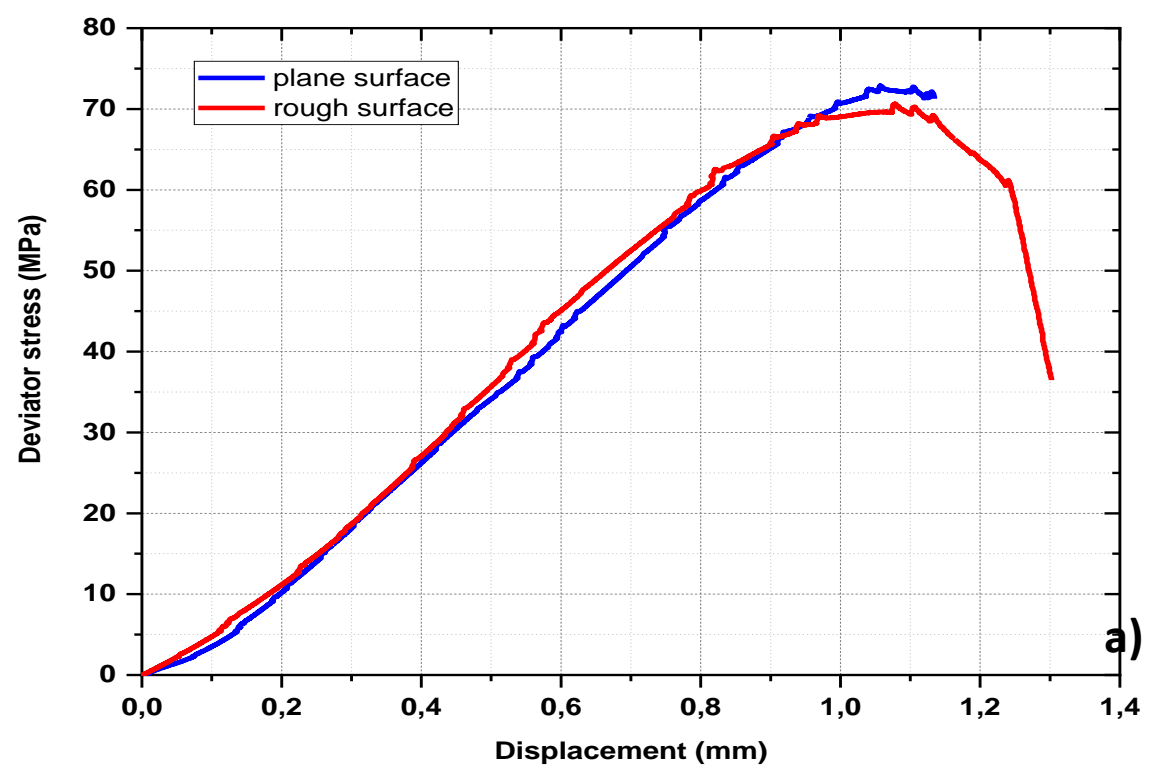

a) specimen of $30^{\circ}$

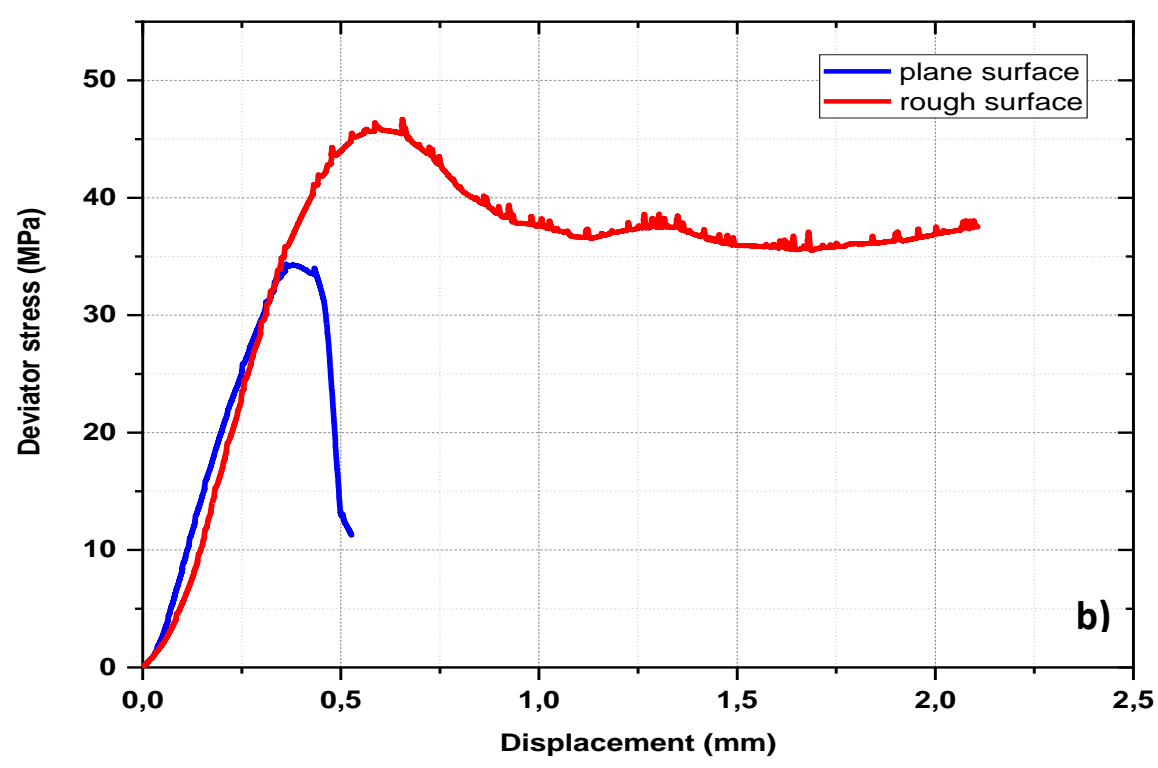

b) specimen of $45^{\circ}$; 


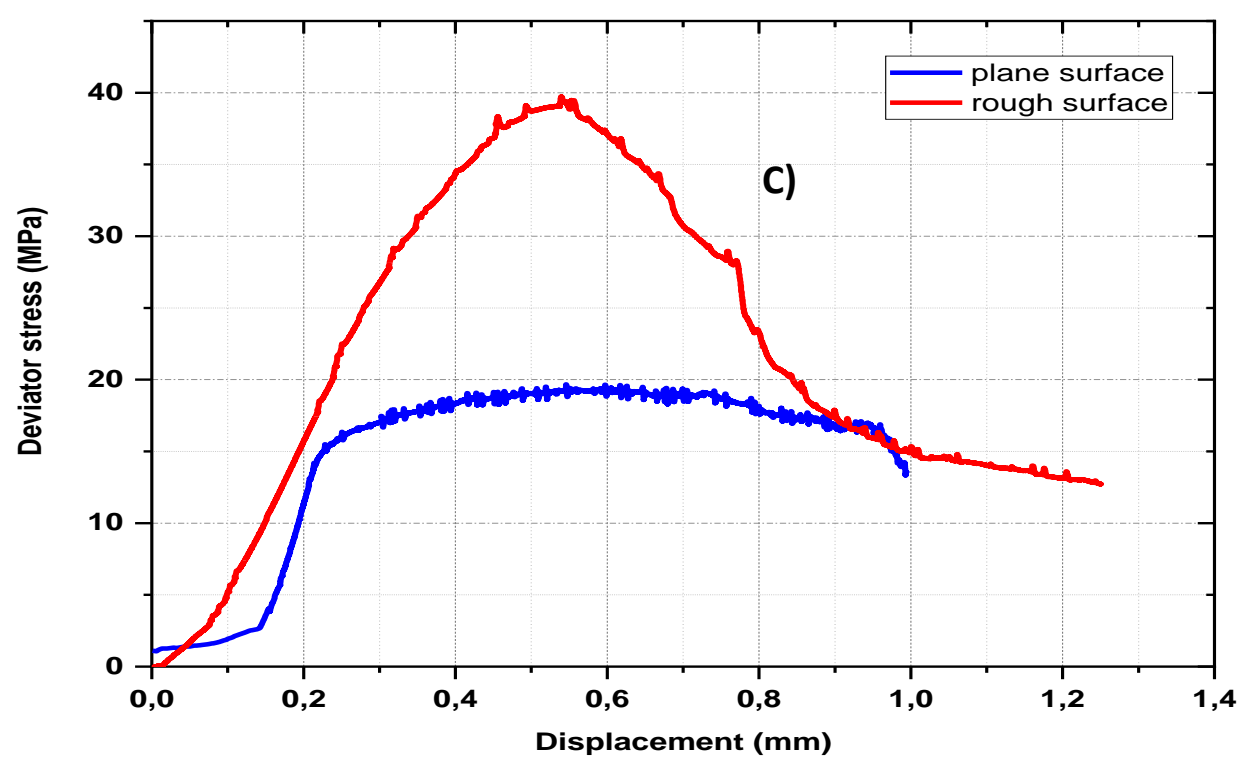

c) specimen of $60^{\circ}$.

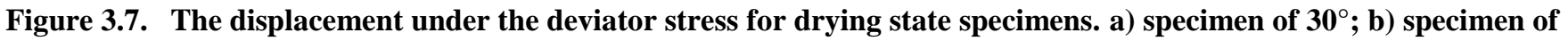
$45^{\circ}$; c) specimen of $60^{\circ}$.

\subsubsection{Stress-displacement of saturated state analysis}

The results of displacement with respect to deviator stress for saturated state are shown in figure 3.8 . Plane surface of $30^{\circ}$ slopes increased lesser than the rough surface in the initial of test. The displacements were increasing along with the deviator stress increase as shown in figure 3.8a. Both plane and rough surface, the specimens increased to displace although the deviator stress decreased. The displacement of $45^{\circ}$ slopes also increased along with the increasing of deviator stress and it kept increasing when the stress decreased as shown in figure $3.8 \mathrm{~b}$. Meanwhile the displacement of $60^{\circ}$ slope specimens can be seen in the figure $3.8 \mathrm{c}$. The plane surface shows different trend with other results where the deviator stress was increases steadily until the end of the test.

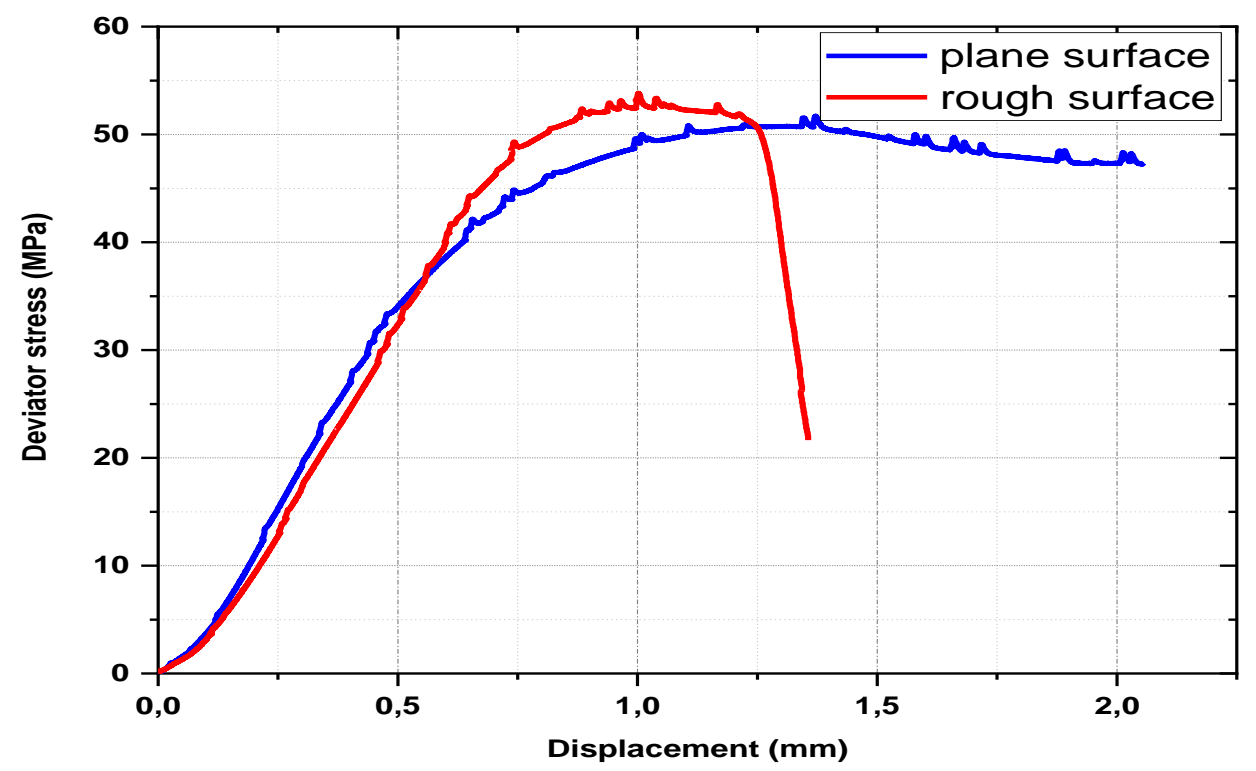

a)

a) specimen of $30^{\circ}$ 


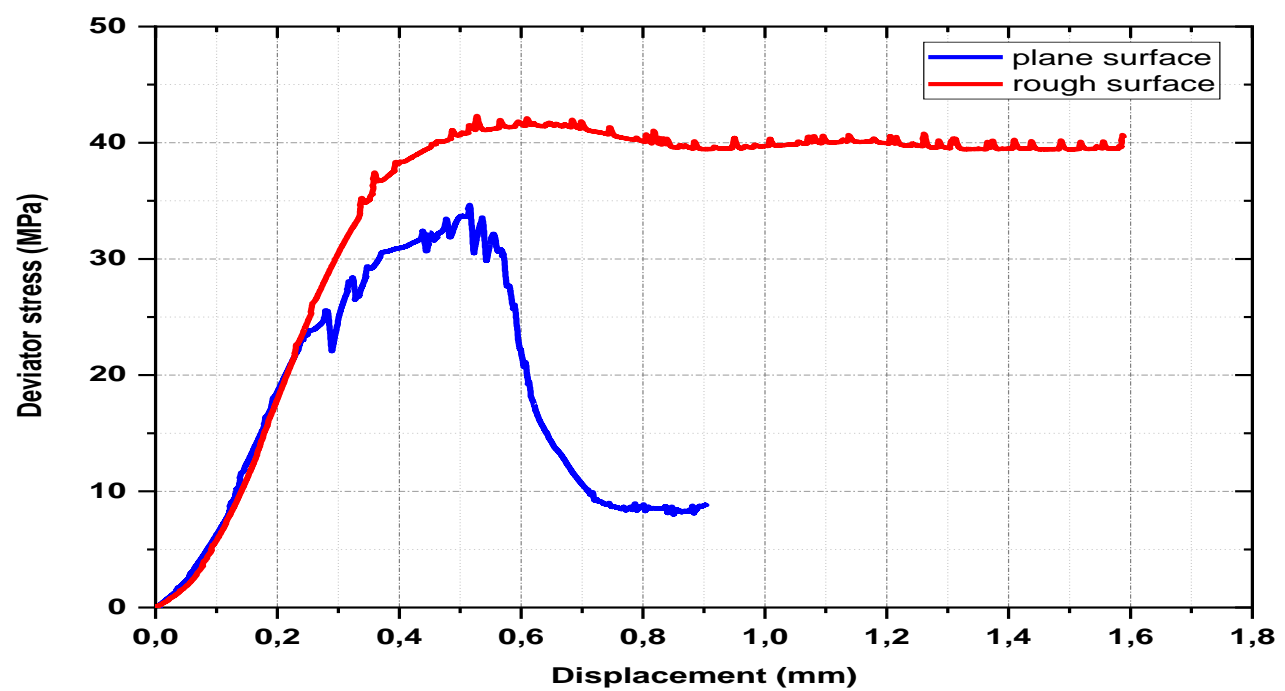

(b)

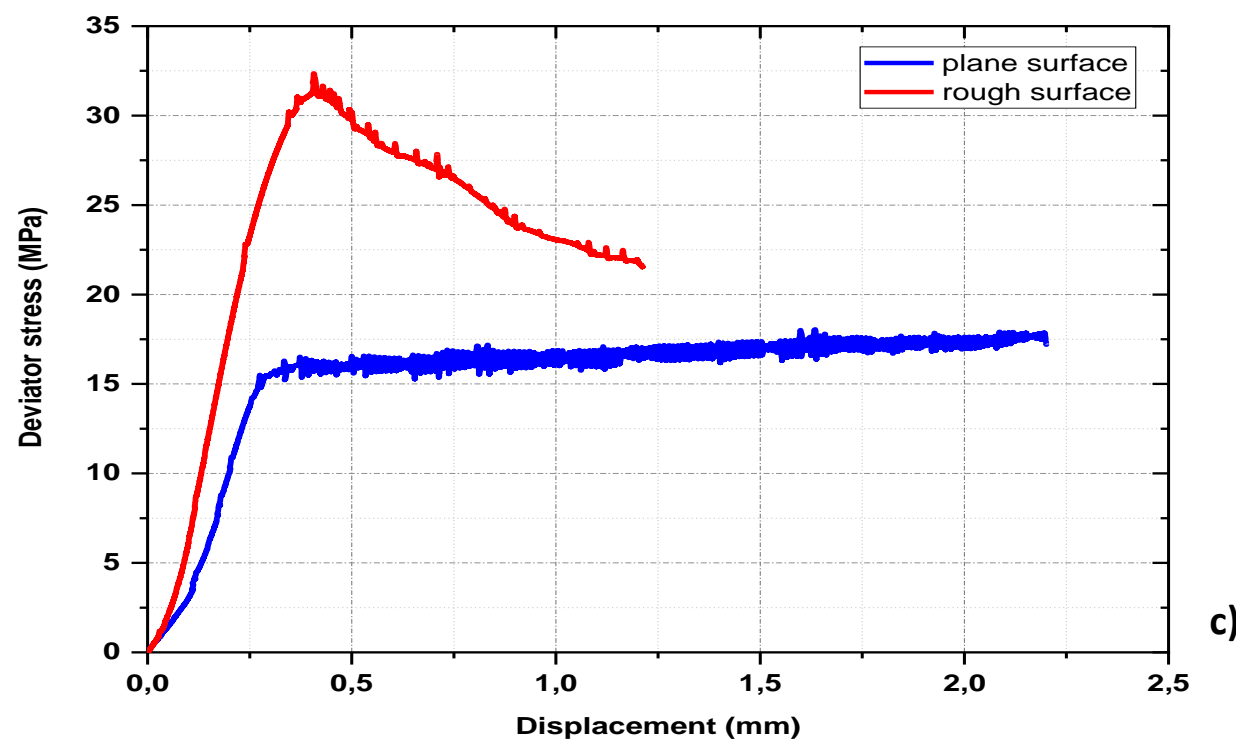

Figure 3.8 Displacement under the deviator stress for saturated state. a) specimen of $30^{\circ}$; b) specimen of $45^{\circ}$; c) specimen $^{\circ}$ of $60^{\circ}$

\subsection{Surface Damage}

Surface topography is generally known to be a set of detailed three-dimensional (3D) features of a certain limited area of surface. The surface topography of the rock joint surface was determined by proposing 3D scanner in order to get illustration of the surface fracture after shear test. Figure 4.1 to 4.4 draw the surface fracture for the drying state specimens. Breaking force took place in the specimen of $30^{\circ}$ slope. The specimen could withstand toward the maximum stress at the 148,604 KPa, further the specimen broke. 

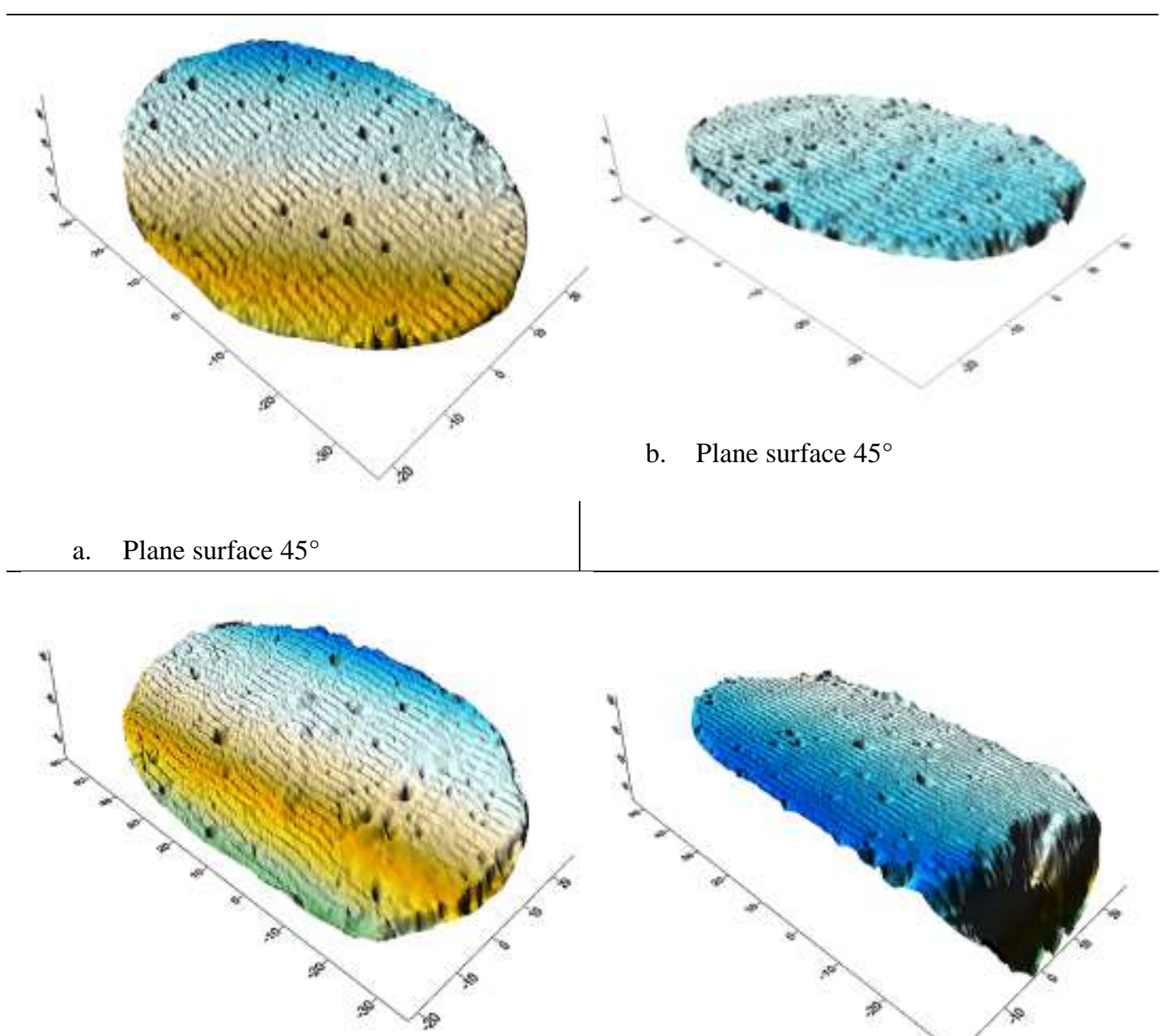

c. Plane surface $60^{\circ}$

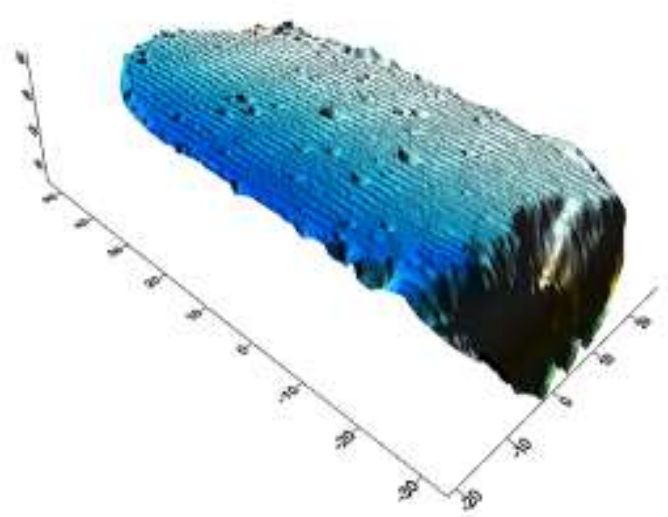

d. Plane surface $60^{\circ}$

Figure 4.1. Topography of plane surface for drying state

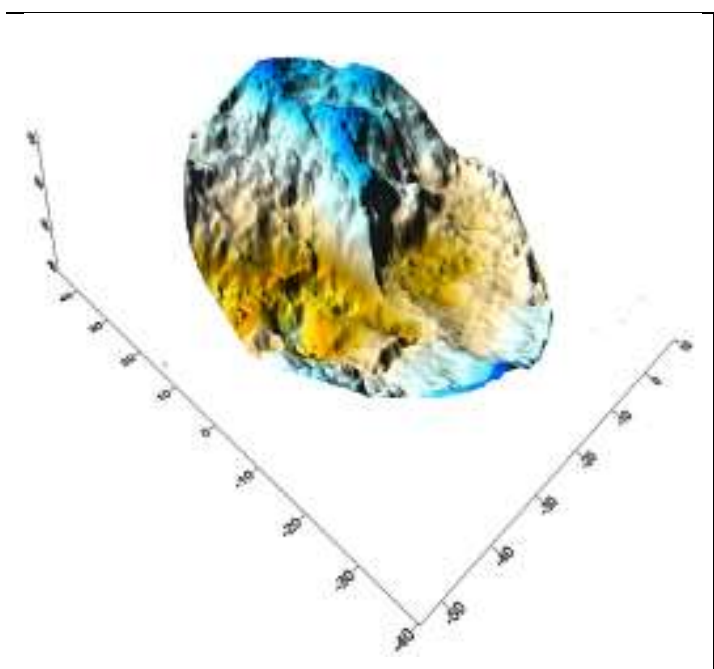

a. Rough surface $45^{\circ}$

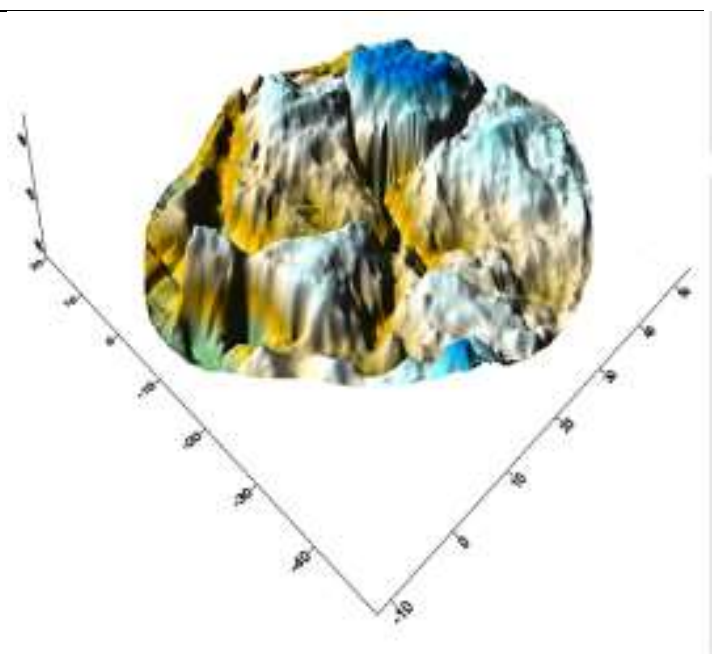

b. Rough surface $45^{\circ}$ 


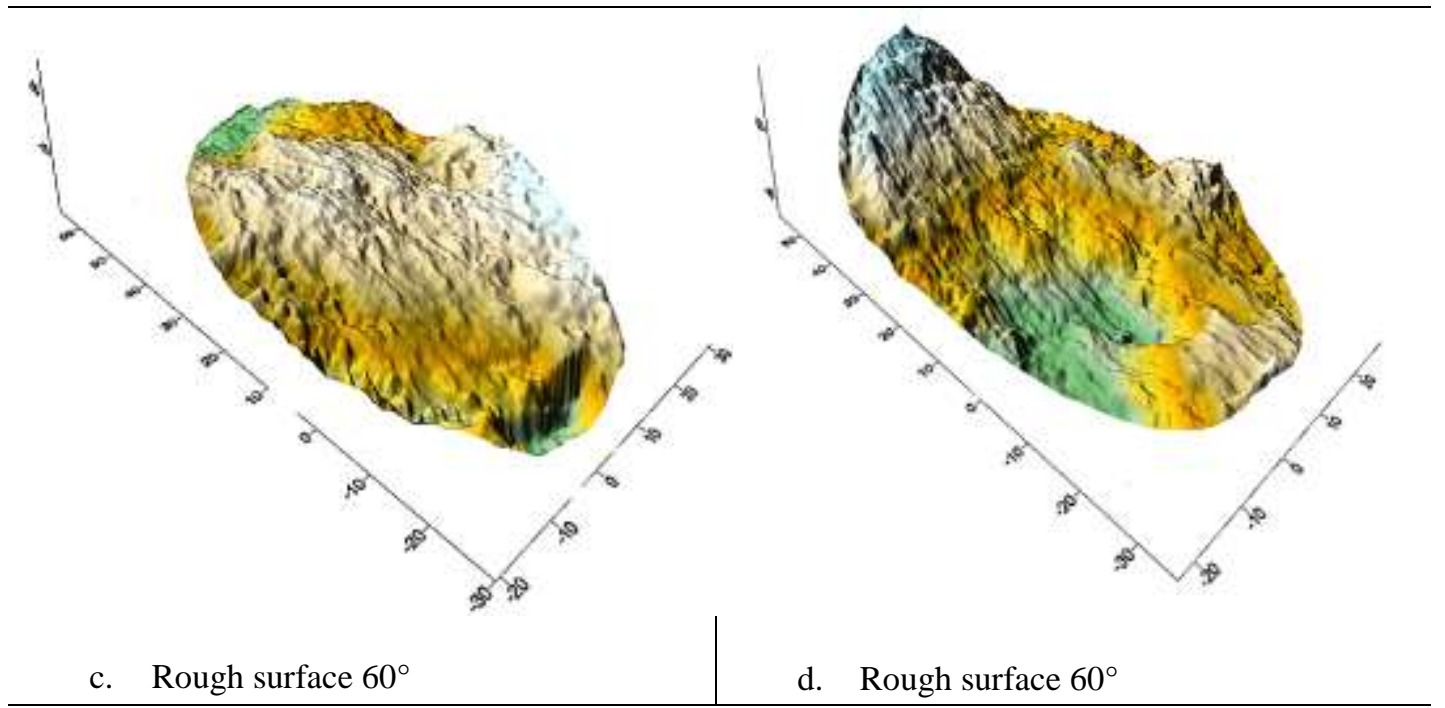

Figure 4.2. Topography of Rough surface for drying state

The plane surface topographies are illustrated clearly from the 3D scanning process in figure 4.1 and the rough surface are drawn in figure 4.2. Fracture apparently occurred for the rough surfaces. Friction between rough surfaces induced fractures rather than plane surface. The rough surface of $45^{\circ}$ shows that though friction on the surface due to the stress given that shape hard coarse and bumpy on the surface. This condition took place in the saturated state specimens as shown in the figure 4.3 and 4.4.

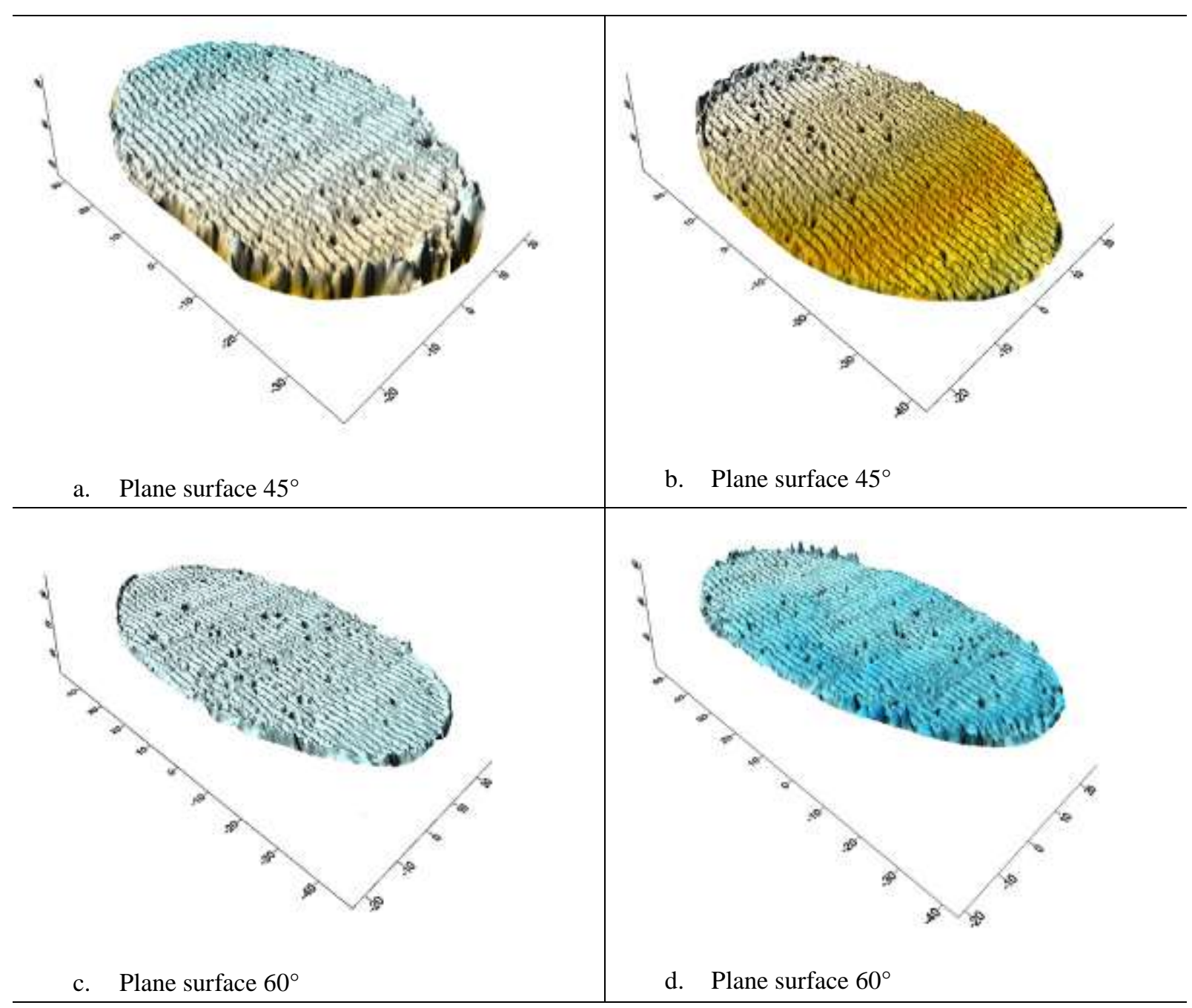

Figure 4.3. Topography of plane surface for saturated state 


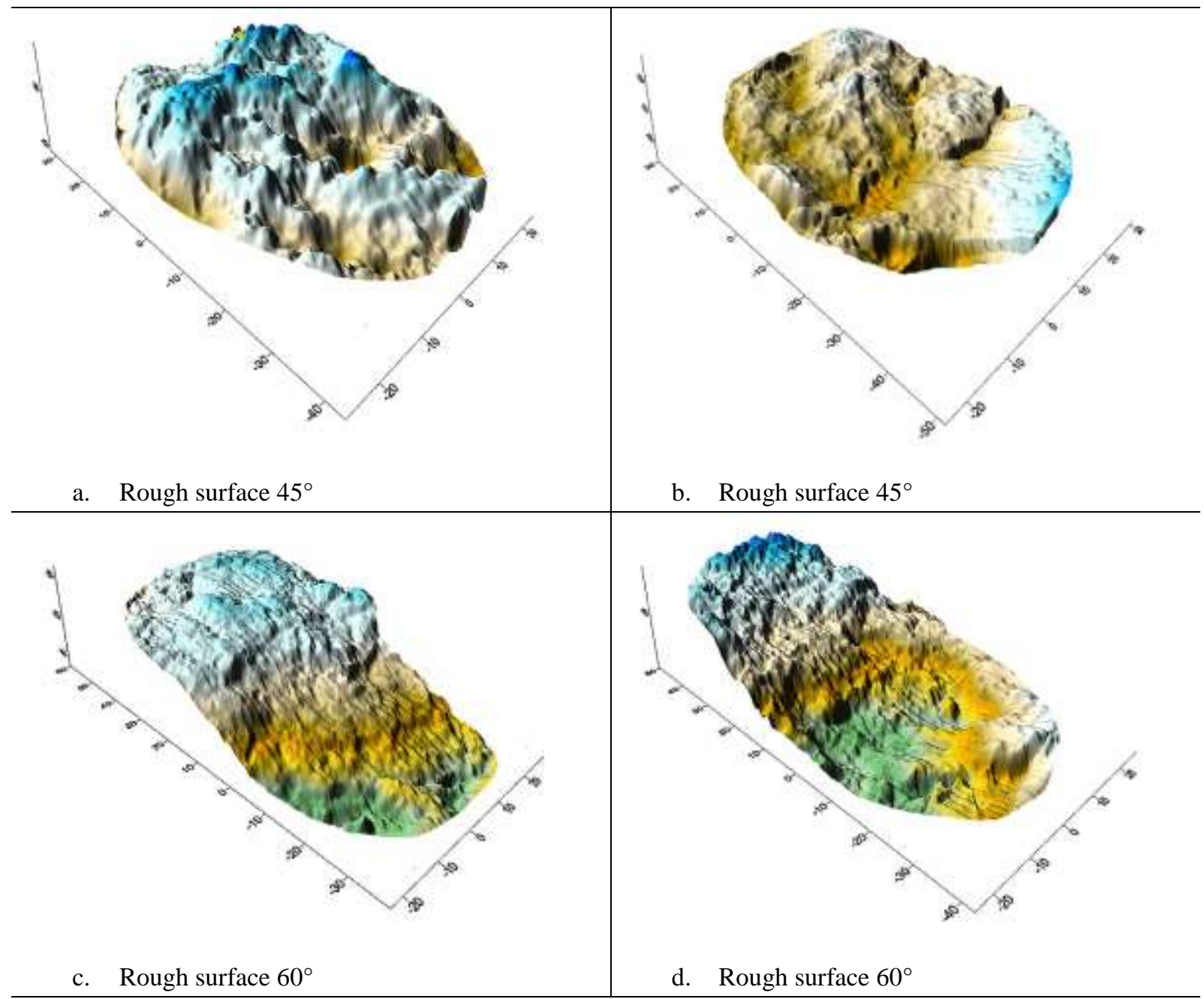

Figure 4.4. Topography of rough surface for saturated state

Abrasive surfaces are visible in the rough surface compared to plane surface specimens. However, the coarse surfaces of drying state apparently are greater than the saturated state specimens. The presence of water brought compactness on the rock decreased the stress and the slip on the joint.

\subsection{Experiment validation}

Experiment is validated by comparing the results with ABAQUS simulation. Concrete Damage Plastic (CDP) model of ABAQUS was applied to define surface friction and identifying the displacement and stress analysis. The comparison between experiment and ABAQUS simulation can be seen in the figure 5.1 and 5.2.

Figure 5.1 shows the comparison results between experiment and simulation for drying state specimens. It can be seen that similar trend appears either for experiment and simulation. The displacement of $45^{\circ}$ slope specimens were $15 \mathrm{~mm}$ under the stress of 40 MPa for the plane surface. The rough surface specimens performed better under the stress because the material displaced slower than plane surfaces. The yield point of $60^{\circ}$ slope of plane specimens was under stress of $50 \mathrm{MPa}$ for both experiment and simulation results while it was approximately under $100 \mathrm{MPa}$ for the rough surfaces. 
International Journal of Advances in Scientific Research and Engineering (ijasre), Vol 7 (4), April -2021

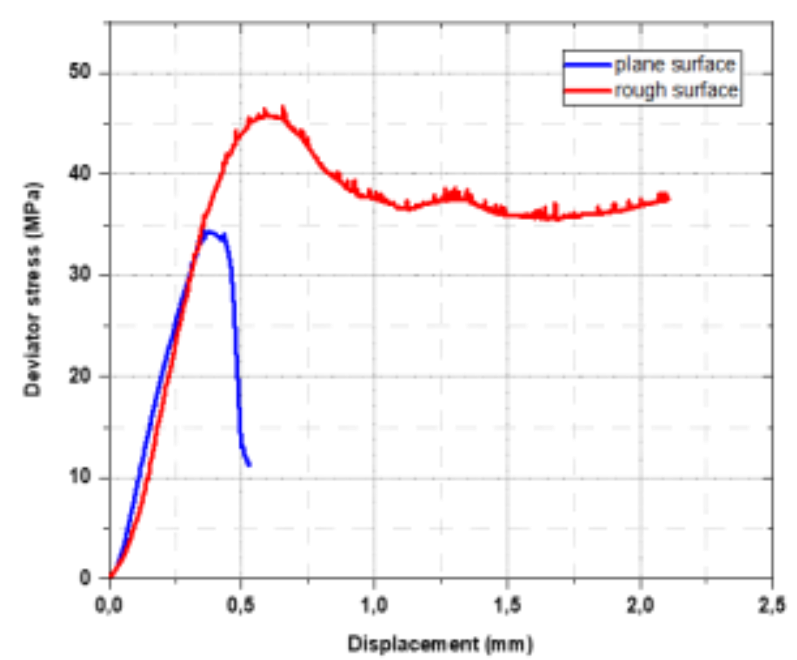

a) Experiment results

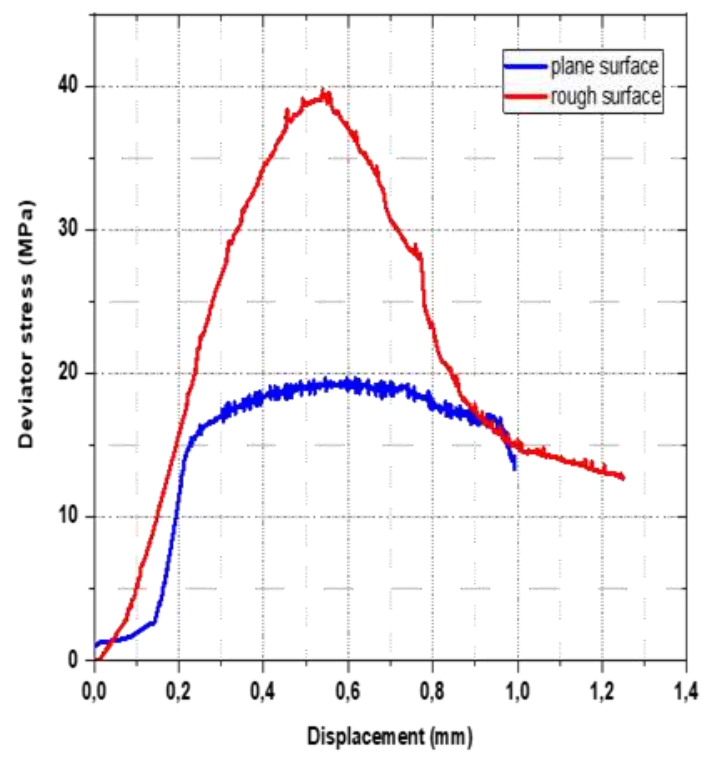

c) Experiment results

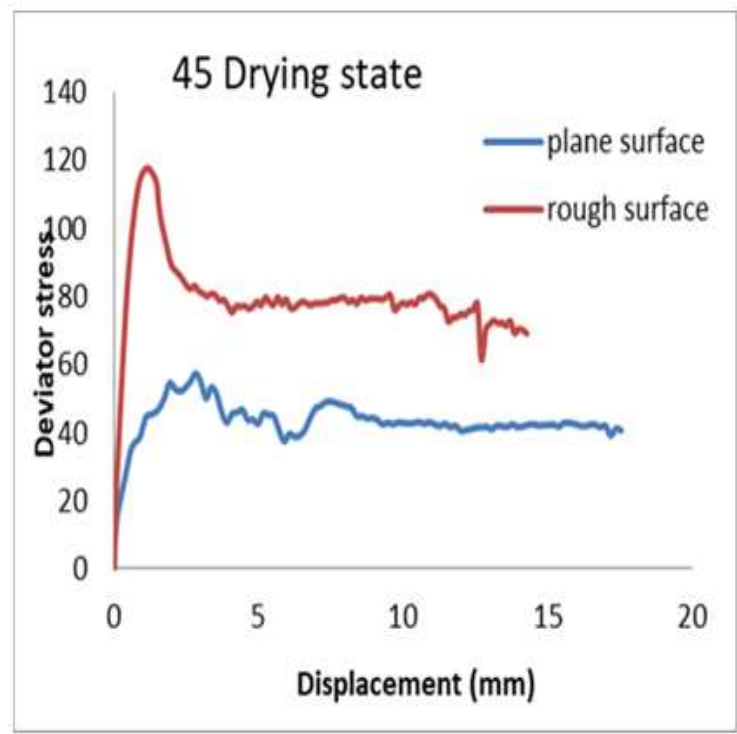

b) Simulation results

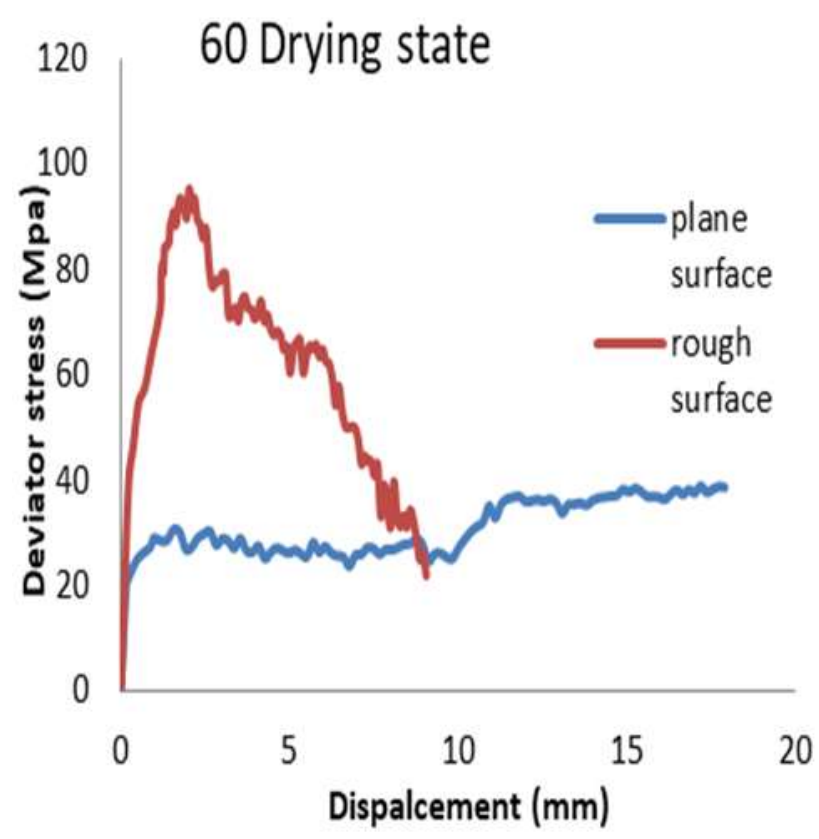

d) Simulation results

Figure 5.1 comparison between experiment and simulation results for drying state 


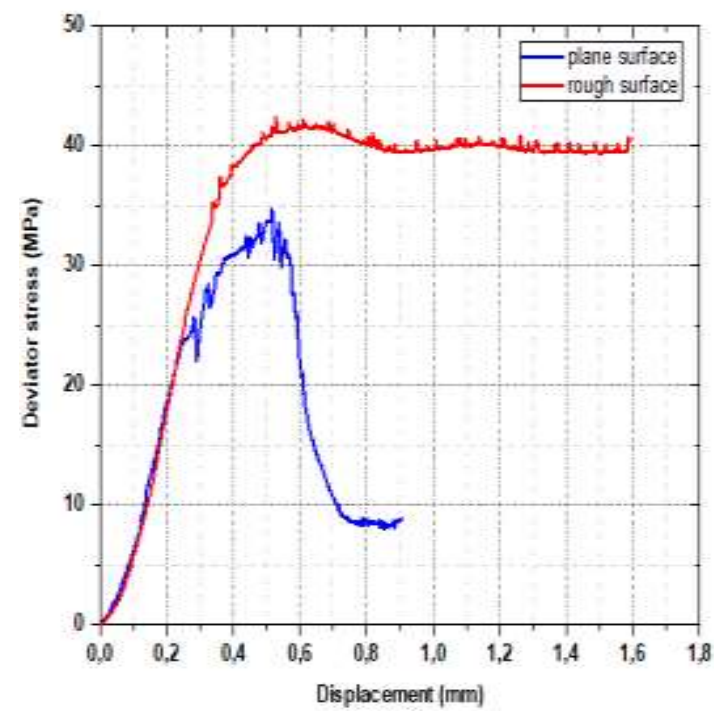

a) Experiment results

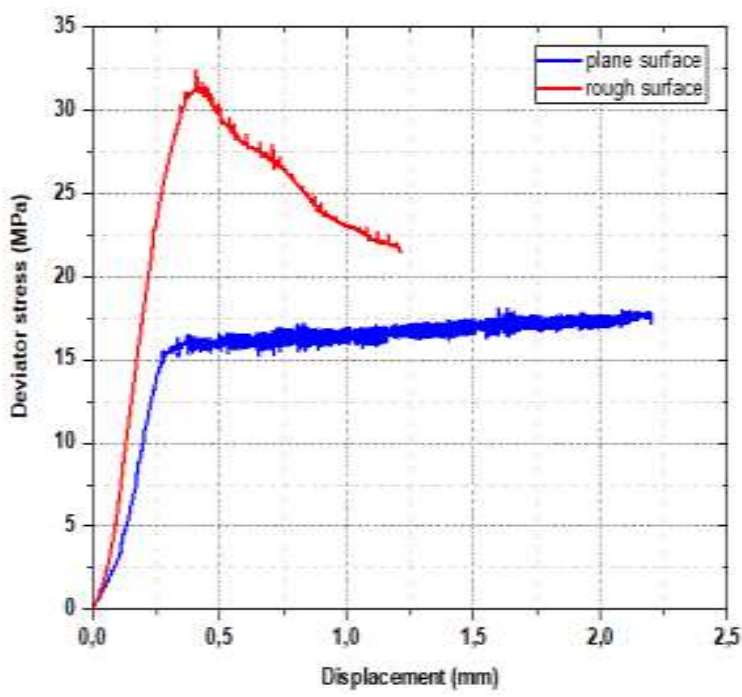

c) Experiment results

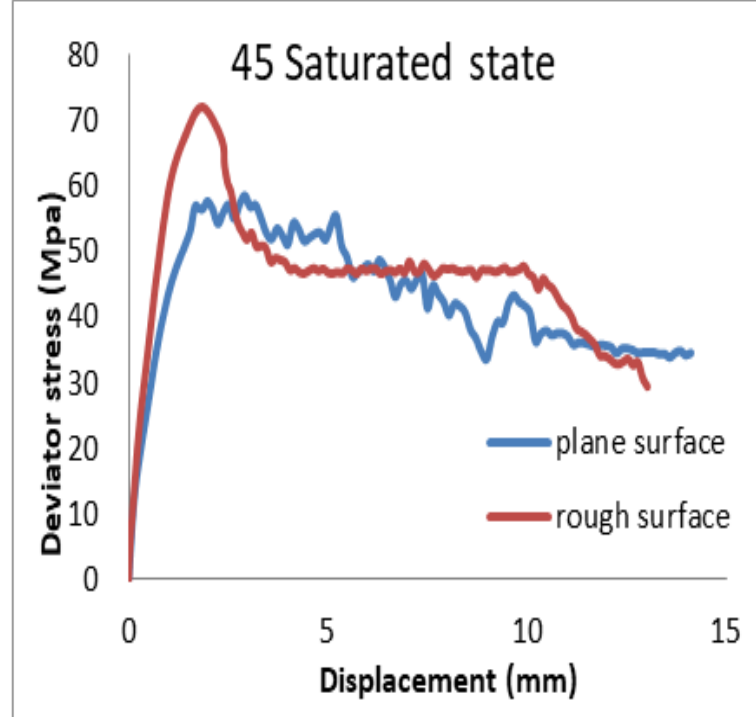

b) Simulation results

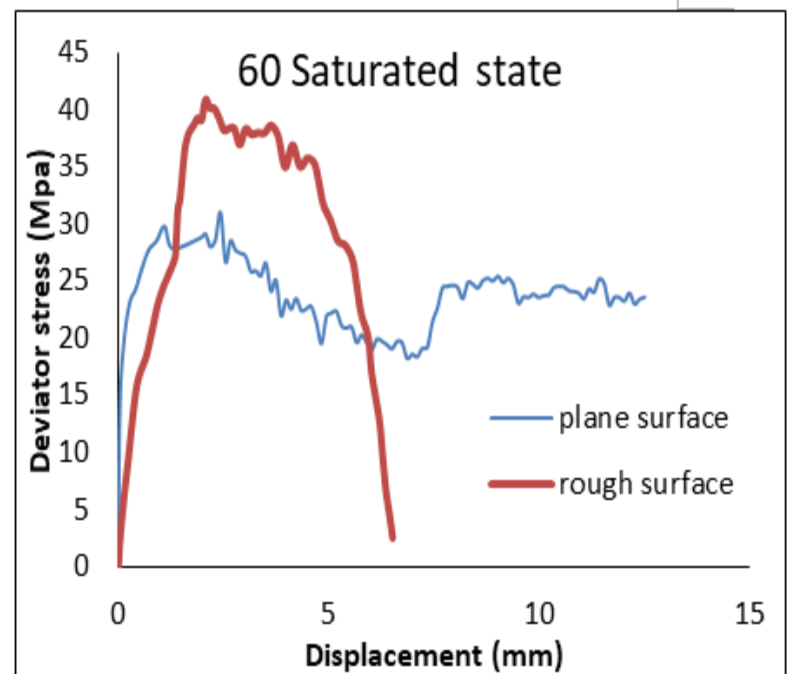

d)Simulation results

Figure 5.2 Comparison between experiment and simulation results for saturated state

The comparison between experiment and simulation results for specimens of saturated state is drawn in the figure 5.2. There can be seen that similar results attained from both methods. The curves of the displacement values under stress which taken from experiment and simulation achieved similar trend. There were no significant difference results which attained by experiment and simulation in all scenarios which were plane surface and rough surface with the slopes of $45^{\circ}$ and $60^{\circ}$.

\section{CONCLUSION}

This paper experimentally investigates the stress, strain, and failure modes of the penetrating fractured rock mass under static load, and to reveal the relationship between its strength, deformation and strain rate, fracture slope, and fracture water. This test was carried out using cement mortar samples. The static loads were applied on two types of fractured rock masses with different slopes.

Based on the results and discussion, it can be concluded that the greater slopes attained greater displacements for both scenarios which were drying and saturated states. The greater slopes caused greater strain on the plane surface specimens of the drying state. It was different with the rough surface results where the relationship between slopes and strains were nonlinear. This happened on the saturated state for either plane or rough surface where the slopes and strains were also nonlinear relationship. Further compressive strength of drying state specimens performed better than saturated state. The results also show that the greater slopes attained lower compressive strength and the rough surface had higher compressive strength compared to plane surface. 
The simulation of ABAQUS was done to retrieve stiffness decrease which caused by damage. This was done to be validated with the experiment results. The displacements of the specimen under deviator stress were taken. The results show that the simulation results attained similar trend with the experiment. It can be concluded that the simulation is feasible get the fracture behavior of the specimens.

\section{REFERENCES}

[1] Barton, N. (1973). Review of a new shear-strength criterion for rock joints. Engineering geology, 7(4), $287-332$.

[2] West, T.R., 1996, The effect of positive pore pressure on sliding and toppling of rock blocks with some consideration of intact rock effects, Environmental and Engineering Geoscience, Vol. II, No. 3, pp. 339-353.

[3] Sullivan, T.D., 2007, Hydromechanical Coupling and Pit Slope Movements, In: Potvin, Y., (ed), Slope Stability, Australian Centre for Geomechanics, Perth.

[4] Yi, L. P., Li, X. G., Yang, Z. Z., \& Waisman, H. (2019). A fully coupled fluid flow and rock damage model for hydraulic fracture of porous media. Journal of Petroleum Science and Engineering, 178, 814-828.

[5] Buocz, I., Rozgonyi-Boissinot, N., Török, Á., \& Görög, P. (2014). Direct shear strength test on rocks along discontinuities, under laboratory conditions. Pollack Periodica, 9(3), 139-150.

[6] Wanniarachchi, W. A. M., Ranjith, P. G., Perera, M. S. A., Rathnaweera, T. D., Zhang, D. C., \& Zhang, C. (2018). Investigation of effects of fracturing fluid on hydraulic fracturing and fracture permeability of reservoir rocks: An experimental study using water and foam fracturing. Engineering Fracture Mechanics, 194, 117-135.

[7] Wanniarachchi, W. A. M., Gamage, R. P., Perera, M. S. A., Rathnaweera, T. D., Gao, M., \& Padmanabhan, E. (2017). Investigation of depth and injection pressure effects on breakdown pressure and fracture permeability of shale reservoirs: an experimental study. Applied Sciences, 7(7), 664.

[8] Al-Quraishi, A., \& Khairy, M. (2005). Pore pressure versus confining pressure and their effect on oil-water relative permeability curves. Journal of Petroleum Science and Engineering, 48(1-2), 120-126.

[9] Jasinge, D., Ranjith, P. G., \& Choi, S. K. (2011). Effects of effective stress changes on permeability of latrobe valley brown coal. Fuel, 90(3), 1292-1300.

[10] Hu, C., Agostini, F., Skoczylas, F., \& Egermann, P. (2018). Effects of gas pressure on failure and deviatoric stress on permeability of reservoir rocks: initial studies on a Vosges sandstone. European Journal of Environmental and Civil Engineering, 22(8), 1004-1022.

[11] Liu, K., \& Sheng, J. J. (2019). Experimental study of the effect of stress anisotropy on fracture propagation in Eagle Ford shale under water imbibition. Engineering Geology, 249, 13-22.

[12] Dahi Taleghani, A., \& Olson, J. E. (2013). How natural fractures could affect hydraulic-fracture geometry. SPE journal, 19(01), 161-171.

[13] Ranjith, P. G., Zhang, C. P., \& Zhang, Z. Y. (2019). Experimental study of fracturing behaviour in ultralow permeability formations: A comparison between CO2 and water fracturing. Engineering Fracture Mechanics, 217, 106541.

[14] Zhou, D., Zhang, G., Prasad, M., \& Wang, P. (2019). The effects of temperature on supercritical CO2 induced fracture: An experimental study. Fuel, 247, 126-134.

[15] Ishida, T., Aoyagi, K., Niwa, T., Chen, Y., Murata, S., Chen, Q., \& Nakayama, Y. (2012). Acoustic emission monitoring of hydraulic fracturing laboratory experiment with supercritical and liquid CO2. Geophysical Research Letters, 39(16).

[16] Ishida, T., Chen, Y., Bennour, Z., Yamashita, H., Inui, S., Nagaya, Y., ... \& Nagano, Y. (2016). Features of CO2 fracturing deduced from acoustic emission and microscopy in laboratory experiments. Journal of Geophysical Research: Solid Earth, 121(11), 8080-8098. 
[17] Kizaki, A., Tanaka, H., Ohashi, K., Sakaguchi, K., \& Matsuki, K. (2012, January). Hydraulic fracturing in Inada granite and Ogino tuff with super critical carbon dioxide. In ISRM Regional Symposium-7th Asian Rock Mechanics Symposium. International Society for Rock Mechanics and Rock Engineering.

[18] Zhou, J., Chen, M., Jin, Y., \& Zhang, G. Q. (2008). Analysis of fracture propagation behavior and fracture geometry using a tri-axial fracturing system in naturally fractured reservoirs. International Journal of Rock Mechanics and Mining Sciences, 45(7), 1143-1152.

[19] Yao, Y., Wang, W., \& Keer, L. M. (2018). An energy based analytical method to predict the influence of natural fractures on hydraulic fracture propagation. Engineering Fracture Mechanics, 189, 232-245.

[20] Zhang, X., \& Jeffrey, R. G. (2006). The role of friction and secondary flaws on deflection and re-initiation of hydraulic fractures at orthogonal pre-existing fractures. Geophysical Journal International, 166(3), 1454-1465.

[21] Gudmundsson, A., Simmenes, T. H., Larsen, B., \& Philipp, S. L. (2010). Effects of internal structure and local stresses on fracture propagation, deflection, and arrest in fault zones. Journal of Structural Geology, 32(11), 1643-1655.

[22] Zhou, J., Huang, H., \& Deo, M. (2016). Numerical study of critical role of rock heterogeneity in hydraulic fracture propagation (No. INL/CON-16-38140). Idaho National Lab.(INL), Idaho Falls, ID (United States).

[23] Warpinski, N. (2011). Fracture growth in layered and discontinuous media. In Proceedings of the Technical Workshops for the Hydraulic Fracturing Study: Fate and Transport. Washington, DC: Environ. Prot. Agency.

[24] Simons, R. N., Ponchak, G. E., Martzaklis, K. S., \& Romanofsky, R. R. (1989, June). Channelized coplanar waveguide: discontinuities, junctions, and propagation characteristics. In IEEE MTT-S International Microwave Symposium Digest (pp. 915918). IEEE.

[25] Larsen, B., Gudmundsson, A., Grunnaleite, I., Sælen, G., Talbot, M. R., \& Buckley, S. J. (2010). Effects of sedimentary interfaces on fracture pattern, linkage, and cluster formation in peritidal carbonate rocks. Marine and Petroleum Geology, 27(7), 1531-1550.

[26] ASTM D4767-95 - Standard Test Method for Consolidated - Undrained Triaxial Compression Test for Cohesive Soils

[27] Barla, G., Barla, M., \& Debernardi, D. (2010). New triaxial apparatus for rocks. Rock mechanics and rock engineering, 43(2), 225-230.

[28] Standard, A. S. T. M. D4767, 2011. Standard test method for consolidated undrained triaxial compression test for cohesive soils. doi, 10 . 